\title{
Immunocytochemical Localization of the GABA Transporter in Rat Brain
}

\author{
Rodica Radian, ${ }^{1}$ Ole Petter Ottersen,, Jon Storm-Mathisen, ${ }^{3}$ Mona Castel, ${ }^{2}$ and Baruch I. Kanner ${ }^{1}$ \\ ${ }^{1}$ The Department of Biochemistry, Hebrew University, Hadassah Medical School, Jerusalem 91010, Israel, 2The \\ Department of Zoology, Institute of Life Sciences, The Hebrew University, Jerusalem, Israel, and ${ }^{3}$ The Anatomical \\ Institute, University of Oslo, N-0162 Oslo 1, Norway
}

Polyclonal antibodies were raised against the GABA transporter (GABA-Tp) purified from rat brain tissue (Radian et al., 1986) and used for immunocytochemical localization of the antigen in several rat brain areas, including the cerebellum, hippocampus, substantia nigra, and cerebral cortex. Light microscopic studies with the peroxidase-antiperoxidase and biotin-avidin-peroxidase techniques suggested that GABA-Tp is localized in the same types of axons and terminals that contain endogenous GABA, as judged by comparison with parallel sections incubated with antibodies against glutaraldehyde-conjugated GABA. However, as expected from biochemical results, different neurons differed in their relative contents of GABA-Tp and GABA; thus, GABATp was relatively low in striatonigral and Purkinje axon terminals and relatively high in nerve plexus around the bases of cerebellar Purkinje cells and hippocampal pyramidal and granule cells. The GABA-Tp antiserum did not produce detectable labeling of nerve cell bodies. Electron microscopic studies supported the light microscopic observations and provided direct evidence of cellular co-localization of GABATp and GABA (as visualized by the peroxidase-antiperoxidase technique and postembedding immunogold labeling, respectively). The ultrastructural studies indicated the presence of GABA-Tp also in glial processes but not in glial cell bodies. The relative intensity of the neuronal and glial staining varied among regions: glial staining predominated over neuronal staining in the substantia nigra, whereas the converse was true in the cerebellum and hippocampus. The present immunocytochemical data demonstrate directly what has previously been inferred from biochemical and autoradiographic evidence: that the mechanisms for high-affinity GABA uptake is selectively and differentially localized in GABAergic neurons and in glial cells.

\footnotetext{
Received Aug. 14, 1989; revised Oct. 23, 1989; accepted Oct. 24, 1989.

This work was supported by grant NS 16708 from the National Institute of Neurology and Communicative Disease and Stroke. Two short-term fellowshipsenabling work by one of us (R.R.) in Oslo from the European Programme in Brain and Behaviour Research, European Science Foundation, and the Fellowship Committee, Hebrew University, Jerusalem - are gratefully acknowledged. We wish to thank Dr. Niels Christian Danbolt for helpful discussions and his help in tissue preparation. Thanks are also due to Bjørg Riber and Anna Torbjørg Bore for expert technical assistance.

Correspondence should be addressed to Baruch I. Kanner, Department of Biochemistry, Hebrew University, Hadassah Medical School, POB 1172 , Jerusalem 91010 , Israel.
}

Copyright (c) 1990 Society for Neuroscience $0270-6474 / 90 / 041319-12 \$ 02.00 / 0$
The GABA transporter (GABA-Tp) is a membrane protein that catalyzes co-transport of sodium, chloride, and GABA (Kanner, 1978, 1983; Radian and Kanner, 1983) and is thought, like other neurotransmitter transporters, to terminate the overall process of synaptic transmission (Iversen, 1971, 1973; Kuhar, 1973; Bennett et al., 1974). Recently, GABA-Tp was purified to apparent homogeneity in functional form (Radian and Kanner, 1985; Radian et al., 1986). It was found to be a glycoprotein with apparent molecular weight of $80 \mathrm{kDa}$. Polyclonal antibodies against $\mathrm{GABA}-\mathrm{Tp}$ were raised in rabbits, reacting specifically with the $80 \mathrm{kDa}$ band and able to immunoprecipitate GABA transport activity (Radian et al., 1986). The aim of the present investigation was to use these antibodies for the immunocytochemical localization of GABA-Tp in brain sections in order to determine (1) whether GABA-Tp is indeed localized to presumed GABAergic neurons, as identified by GABA immunocytochemistry (Storm-Mathisen et al., 1983) applied to the same or adjacent sections, (2) whether, in addition, other structures contain the transporter, and (3) if possible, how the molecule is distributed within the cells that contain it.

\section{Materials and Methods}

Antisera. The GABA-Tp antibody was prepared by immunizing rabbits with pure transporter as described previously (Radian et al., 1986). Since the crude antiserum gave high background, it was affinity-purified by binding to an Affi-gel 15 column (Bio-Rad) carrying the transporter, partially purified by ammonium sulfate fractionation, and DEAE chromatography (Radian and Kanner, 1985). The partially purified transporter, $1 \mathrm{mg}$ (about 5-6 ml), was mixed with $1 \mathrm{ml}$ Affi-gel in the presence of $1.5 \mathrm{ml} 0.4 \mathrm{M} \mathrm{Na}$-Hepes, $\mathrm{pH} 7.4$, for $4 \mathrm{hr}$ at $0^{\circ} \mathrm{C}$. Coupling was terminated by adding $0.3 \mathrm{ml} 1 \mathrm{M}$ ethanolamine, $\mathrm{pH} 8$, and mixing for $1 \mathrm{hr}$ at $0^{\circ} \mathrm{C}$. The coupled material was washed with 3 column volumes of PBS (140 mM NaCl, $5 \mathrm{~mm} \mathrm{KCl,} 5 \mathrm{~mm}$ Na-phosphate buffer, pH 7.4). The crude serum containing anti-GABA-Tp antibodies was passed through the column $(4 \mathrm{ml}$ serum/ $1 \mathrm{ml}$ Affi-gel), which was then rinsed

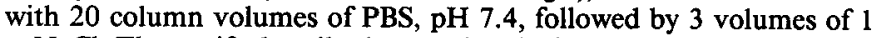
$\mathrm{M} \mathrm{NaCl}$. The purified antibody was eluted with $0.2 \mathrm{M} \mathrm{HCl}-\mathrm{glycine}, \mathrm{pH}$ 2.7 , and neutralized with 0.3 volumes of $0.4 \mathrm{M} \mathrm{Na}_{2} \mathrm{HPO}_{4}$ per volume of eluate. This eluate was used at a dilution of 1:10. The anti-GABA serum no. 26 was purified as described (Storm-Mathisen et al., 1983; Ottersen and Storm-Mathisen, 1984a) and diluted 1:300 when used with the peroxidase-antiperoxidase (PAP) method (reagents from $\mathrm{Da}$ kopatts) or 1:3000 when used with the avidin-biotin complex (ABC) kit (Vector).

Fixation. Adult Wistar rats $(150-250 \mathrm{gm})$ were perfused through the ascending aorta at room temperature as described previously (Ottersen and Storm-Mathisen, 1984a, c) with one of the following fixatives in $0.1 \mathrm{~m}$ Na-phosphate buffer, pH 7.4 (light microscopy), or $0.1 \mathrm{~m} \mathrm{Na}$ cacodylate, pH 7.4 (electron microscopy): (1) 5\% glutaraldehyde; (2) 4\% formaldehyde (freshly depolymerized from paraformaldehyde) $+0.2 \%$ glutaraldehyde; (3) $3 \%$ glutaraldehyde +2 or $3 \%$ formaldehyde. All fixatives mentioned (plus a number of others, with different aldehyde 


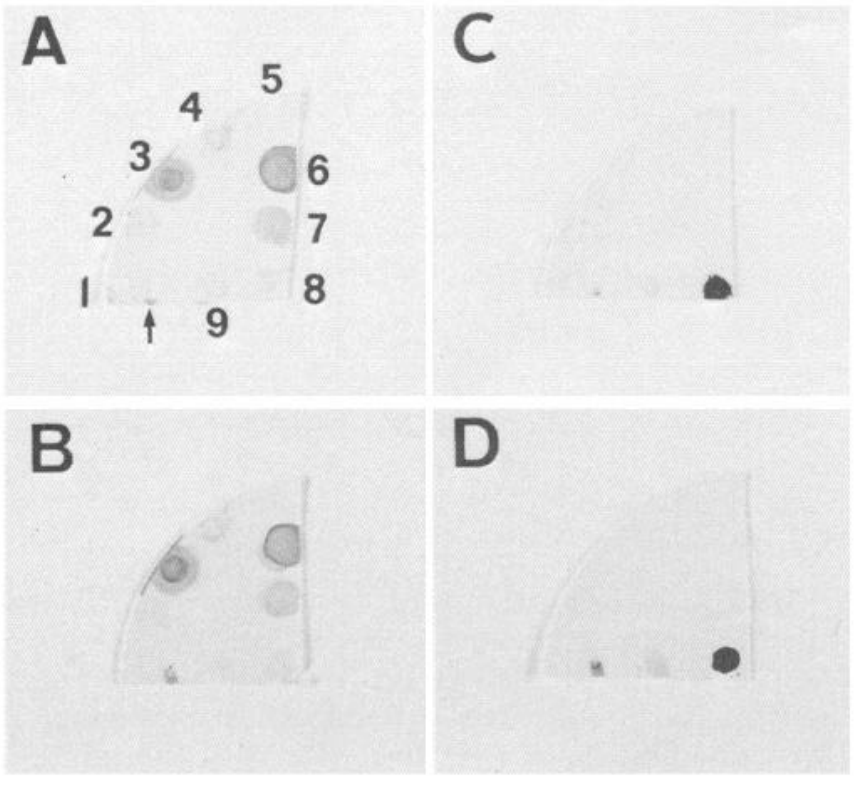

Figure 1. Characteristics of antisera raised against purified GABA-Tp $(A, B)$ and against glutaraldehyde-conjugated GABA $(C, D)$. GABA-Tp at different degrees of purification, and GABA fixed to rat brain macromolecules, were spotted on quadrants of $13 \mathrm{~mm}$ Millipore filters. The filters were processed either with purified GABA-Tp antiserum at a 1: 10 dilution $(A, B)$ or with GABA antiserum at a 1:300 dilution $(C, D)$, and developed by the PAP method as described by Ottersen and StormMathisen (1984a). The protein and amino acids spots were as follows: $I$ and 2, flowthrough of the DEAE column (Radian and Kanner, 1985), containing 0.2 and $0.45 \mu \mathrm{g}$ protein per spot, respectively, but no GABA transport activity; 3, GABA-Tp activity peak fraction of the DEAE column, containing $0.25 \mu \mathrm{g}$ protein; 4 , a fraction from the DEAE column containing $0.15 \mu \mathrm{g}$ protein and very little GABA-Tp activity; 5 , the elution buffer of the DEAE column (10 mM KPi, pH 6.8, $0.2 \%$ Triton $\mathrm{X}-100,50 \mathrm{~mm} \beta$-octylglucoside); 6 and 7, GABA-Tp activity peak fractions after wheat germ-agglutinin Sepharose 4B chromatography, containing 0.1 and $0.06 \mu \mathrm{g}$ protein, respectively; 8 , GABA conjugated to brain macromolecules ( $0.8 \mu \mathrm{g}$ protein; starting concentration of GABA $2.5 \mu \mathrm{mol} / \mathrm{mg}$ protein, i.e., 100 times the average GABA level in brain) by glutaraldehyde; 9 , null, i.e., glutaraldehyde-treated brain macromolecules $(0.8 \mu \mathrm{g}$ protein). Arrow, orientation mark. Spots represent 0.1 $\mu \mathrm{l}$ of solutions (applied repetitively for spots $3-7$ ). The solutions 1-7 were dialyzed against $2 \mathrm{mM} \mathrm{KPi}$, pH 6.8, and concentrated 10 times, but since they still contained traces of detergents, large spots were formed. Before incubation with the antisera, the spotted filters were reacted with fixatives used in the preparation of tissue specimens: (1) $5 \%$ glutaraldehyde $(A, C)$ or $(3) 2 \%$ formaldehyde $+3 \%$ glutaraldehyde $(B, D)$. Note that staining by the GABA-Tp antiserum is selective for the transporter and depends on the GABA-Tp concentration but not on the fixative.

ratios) gave similar light microscopic distributions of immunoreactivities, although fixative 2 gave somewhat stronger staining for the GABA$T p$, than 1 and 3 . Fixatives 1 and 3 were preferred for the ultrastructural studies since they provided the best tissue preservation. After perfusion, brains were removed and, for light microscopy, kept in the same fixative overnight at $4^{\circ} \mathrm{C}$. Vibratome sections $(25 \mu \mathrm{m})$ were collected in $0.1 \mathrm{M}$ Na-phosphate buffer, pH 7.4. For electron microscopy the brains were kept in the fixative for 1-2 hr, and then 50- to $60-\mu \mathrm{m}$-thick Vibratome sections were cut and processed as described below.

Light microscopy. Free-floating Vibratome sections and cellulose ester test filters were processed by the PAP method (Sternberger, 1979) as described by Ottersen and Storm-Mathisen (1984a) or by the ABC method (Hsu et al., 1981) using biotinylated secondary antibody and peroxidase conjugated to avidin. For some experiments with the PAP method the incubation with secondary antibody followed by PAP complex and diaminobenzidine $/ \mathrm{H}_{2} \mathrm{O}_{2}$ were repeated ("double PAP"). These different procedures gave qualitatively the same results. All buffers $(0.1$
M Na-phosphate, $\mathrm{pH} 7.4$ ) contained $1 \%$ normal sheep serum (3\% in the preincubation buffer). Incubation with the primary antibody was carried out overnight at room temperature, and antibody penetration was augmented by including $0.5 \%$ Triton $\mathrm{X}-100$ with the sera $(0.1 \%$ Triton $\mathrm{X}-100$ was used in all other steps). The sections were viewed and photographed in bright-field in a Nikon Optiphot microscope; low-magnification pictures (Figs. 1-3) were taken with a Nikon Multiphot.

Electron microscopy. Pre-embedding immunoperoxidase labeling was carried out essentially as for light microscopy, using the ABC kit, but Triton X-100 was omitted at all steps. In some experiments, $0.1 \mathrm{M} \mathrm{Na}$ cacodylate, $\mathrm{pH} 7.4$, was used instead of the Na-phosphate buffer. The peroxidase reaction with diaminobenzidine and $\mathrm{H}_{2} \mathrm{O}_{2}$ was allowed to develop for a relatively short time (1-2 $\mathrm{min})$, so that only faint staining was observed at the light microscopic level. Only the outer $1-2 \mu \mathrm{m}$ of the embedded sections was examined, due to the limited penetration of the immunoreagents. Immunolabeled sections were postfixed in $\mathrm{OsO}_{4}$ ( $1 \%$ in Na-cacodylate buffer) for $1 \mathrm{hr}$, dehydrated with ascending concentrations of ethanol and flat-embedded in Spurr's resin (EMS) or Epon 812 (Agarscientific), there being no obvious difference between resins. Thin sections were observed and photographed using a Philips 300 or a Philips CM 10 electron microscope at 60 or $80 \mathrm{kV}$, respectively.

\section{Postembedding immunogold labeling}

Thin sections of specimens labeled with GABA-Tp antibodies (preembedding, ABC procedure) at a 1:10 dilution were partly deosmicated with $10 \%$ periodic acid for $6 \mathrm{~min}$. Subsequently, they were treated with GABA antiserum 26 at a 1:50 dilution ( $90 \mathrm{~min}$, room temperature) and with goat anti-rabbit IgG labeled with gold particles (GAR-10 nm, Biocell, Cardiff) at a 1:5 dilution (60 min, room temperature) as described by Castel et al. (1985).

\section{Results}

\section{Specificity of antibodies}

The specificity of anti-GABA-Tp was tested on cellulose ester filters using a variety of antigens (Fig. 1). Anti-GABA-Tp recognized the partially purified (about a 100-fold; cf. Radian and Kanner, 1985) GABA-Tp after the DEAE column step (Fig. 1, $A, B$, spot 3 ) or the purified transporter after the lectin column (spots 6,7) (about a 1000-fold purification; Radian et al., 1986). The antibody did not react with fractions devoid of GABA transport activity, such as the flowthrough of the DEAE column (spots 1,2), or fractions eluted after the peak of activity (spot 4). Anti-GABA-Tp reacted neither with the buffer in which the transporter was solubilized and eluted (spot 5) nor with rat brain protein conjugates of GABA or other amino acids with glutaraldehyde (spots 8,9 ). (These conjugates were prepared from a total brain extract and must therefore be assumed to contain GABA-Tp. However, the proportion of GABA-Tp in the conjugates is obviously so low as to escape immunocytochemical detection.) The choice of fixative 1 or 3 did not affect the GABATp immunoreactivity (Fig. 1, $A, B$ ). GABA antiserum no. 26 reacted only with conjugated GABA (Fig. 1, $C, D$, spot 8 ). (The concentration of antigens in the spots differ from those in the tissues; the staining intensities in Fig. 1 should not be compared to those in the other figures.)

When partially purified GABA-Tp was added at the incubation step with GABA-Tp antiserum, there was strong inhibition of immunoreactivity in tissue sections (Fig. 2). When preimmune serum was used, or the primary antibody omitted, no immunoreactivity could be detected (not shown). As previously reported, glutaraldehyde-reacted GABA $(100-300 \mu \mathrm{m})$, but not other amino acids, abolished immunoreactivity when added to the GABA antiserum at the preembedding light microscopic (Ottersen et al., 1986), as well as at the postembedding electron microscopic level (Ottersen et al., 1988). 


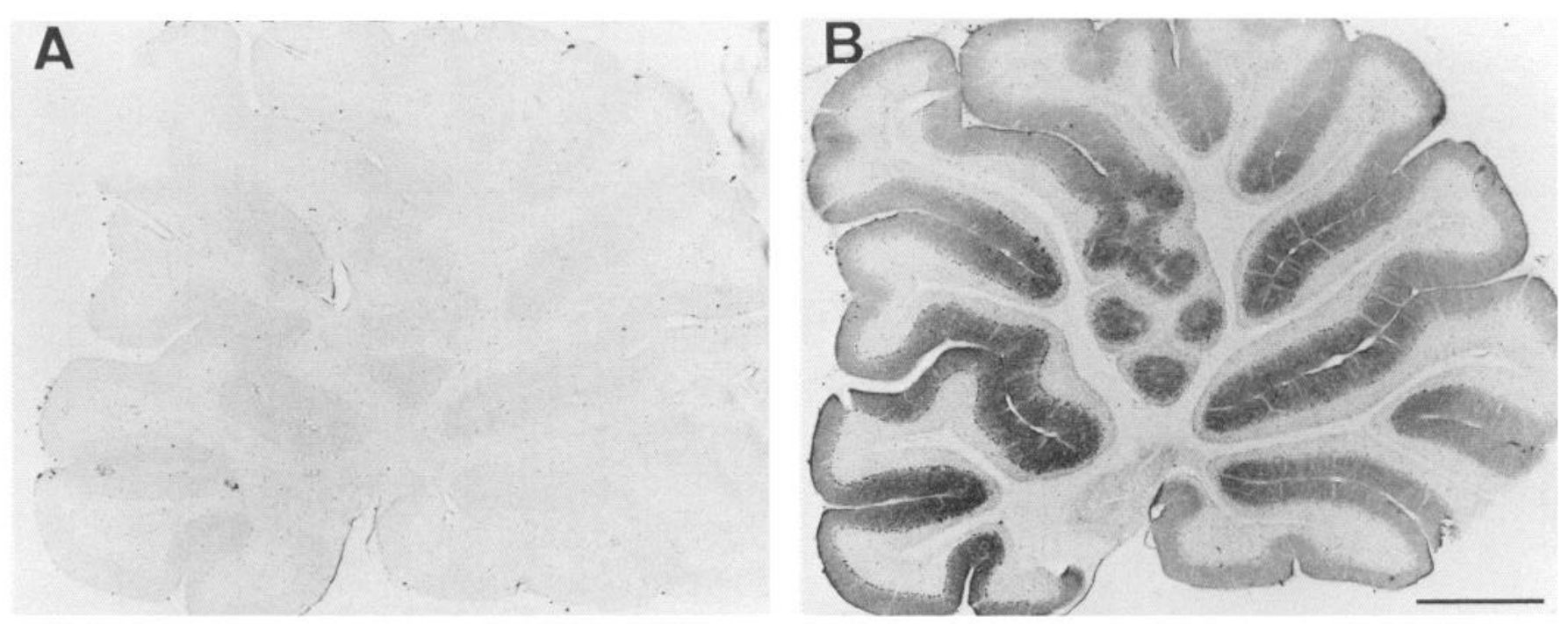

Figure 2. Absorption of the GABA-Tp antibody with the partially purified transporter completely blocks GABA-Tp immunoreactivity. Adjacent parasagittal sections of cerebellum were incubated with the purified antibody (diluted 1:10) in the presence $(A)$ or absence $(B)$ of partially purified GABA-Tp $(0.2 \mathrm{mg} / \mathrm{ml}, 0.25 \mu \mathrm{M})$. Tissue fixed with $4 \%$ formaldehyde $+0.2 \%$ glutaraldehyde. Scale bar, $1 \mathrm{~mm}$.

\section{Light microscopic localization of the transporter}

Immunoreactivity for GABA-Tp, as well as for GABA itself, occurred in what appeared to be axons and axon terminals (Figs. $3-6)$. The patterns of neuropil staining for the 2 antigens showed

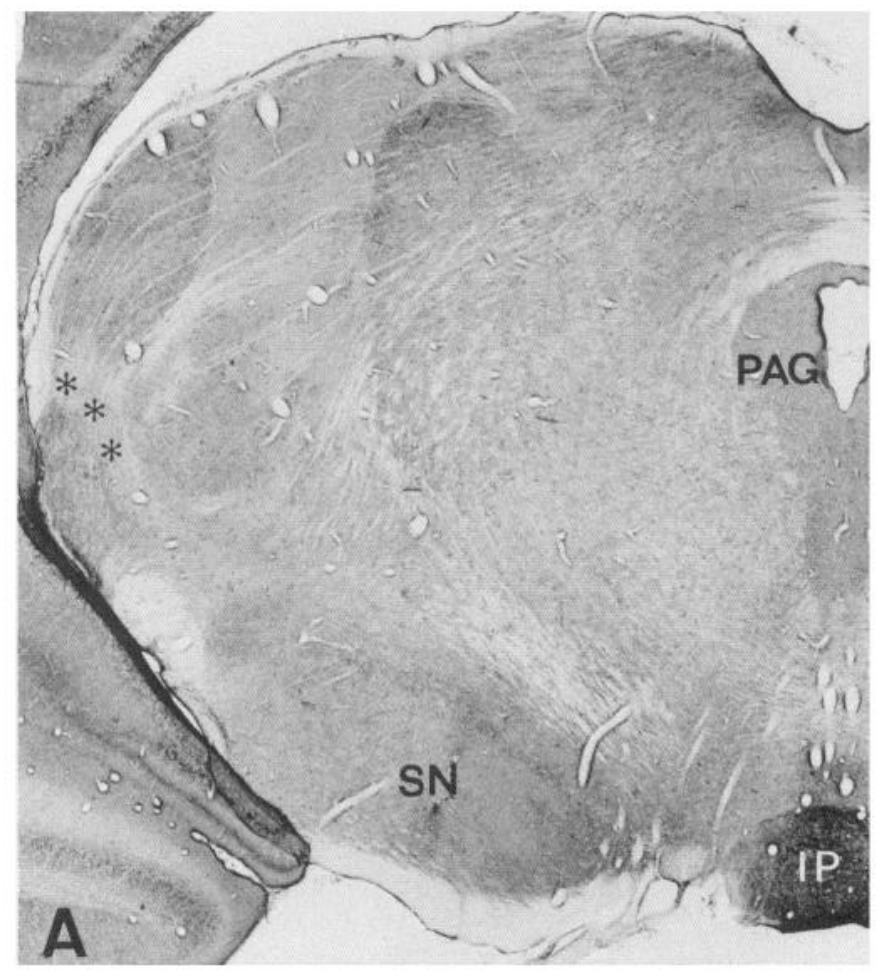

striking similarities in all the brain areas tested, in agreement with the immunocytochemically described distributions of GABA (Ottersen and Storm-Mathisen, 1984a) and GAD (Mugnaini and Oertel, 1985) in neuropil. However, no GABA-Tppositive cell bodies could be detected in any of the areas.

Figure 3. Distribution of the immunoreactivities of GABA-Tp $(A)$ and GABA $(B)$ in the diencephalon/mesencephalon. Adjacent transverse sections of brains fixed with 5\% glutaraldehyde were incubated with the antibodies diluted 1:10 and 1:300, respectively; double PAP. Abbreviations: $A P$, anterior pretectal nucleus; $I P$, interpeduncular nucleus; $L G d$ and $L G v$, dorsal and ventral subdivisions of the lateral geniculate bodies; $L P$, lateroposterior thalamic nucleus; $M L$, medial lemniscus; $N O T$, nucleus of the optic tract; $O P$, olivary pretectal nucleus; $P O$, posterior thalamic complex; $P P$, posterior pretectal nucleus; $S N c$ and $S N r$, pars compacta and pars reticulata of substantia nigra; asterisks, intergeniculate leaflet (Ohara et al., 1983). For nomenclature, see Scalia (1972, pretectum) and Jones (1983, thalamus). Note that, with some exceptions (see text), GABATp and GABA show above average staining in the same areas. Scale bar, $500 \mu \mathrm{m}$. 
Figure 4. Immunoreactivities of GABA-Tp $(A)$ and GABA $(B)$ in closely spaced sections of the dorsal part of the hippocampal formation, showing CA1, area dentata and a small part of CA3. Specimen preparation as in Figure 3. Abbreviations: $O, P, R, L M, L U$, strata oriens, pyramidale, radiatum, lacunosum-moleculare, and lucidum of hippocampus; $\mathrm{Mo}, \mathrm{Mm}, \mathrm{Mi}, \mathrm{G}$, strata moleculare (outer, middle, and inner parts) and granulare of area dentata; $H$, deep hilar region; asterisks, fissura hippocampi (i.e., cortical surface); open stars, artifactual contour due to fold in section. Note that the laminar staining patterns are principally similar for GABATp and GABA, but differ in details (see text). Also note predominance of fibers, particularly at basal aspects of pyramidal and granular cell layers in $A$ and presence of stained neuronal cell bodies in $B$. Scale bar, $100 \mu \mathrm{m}$.
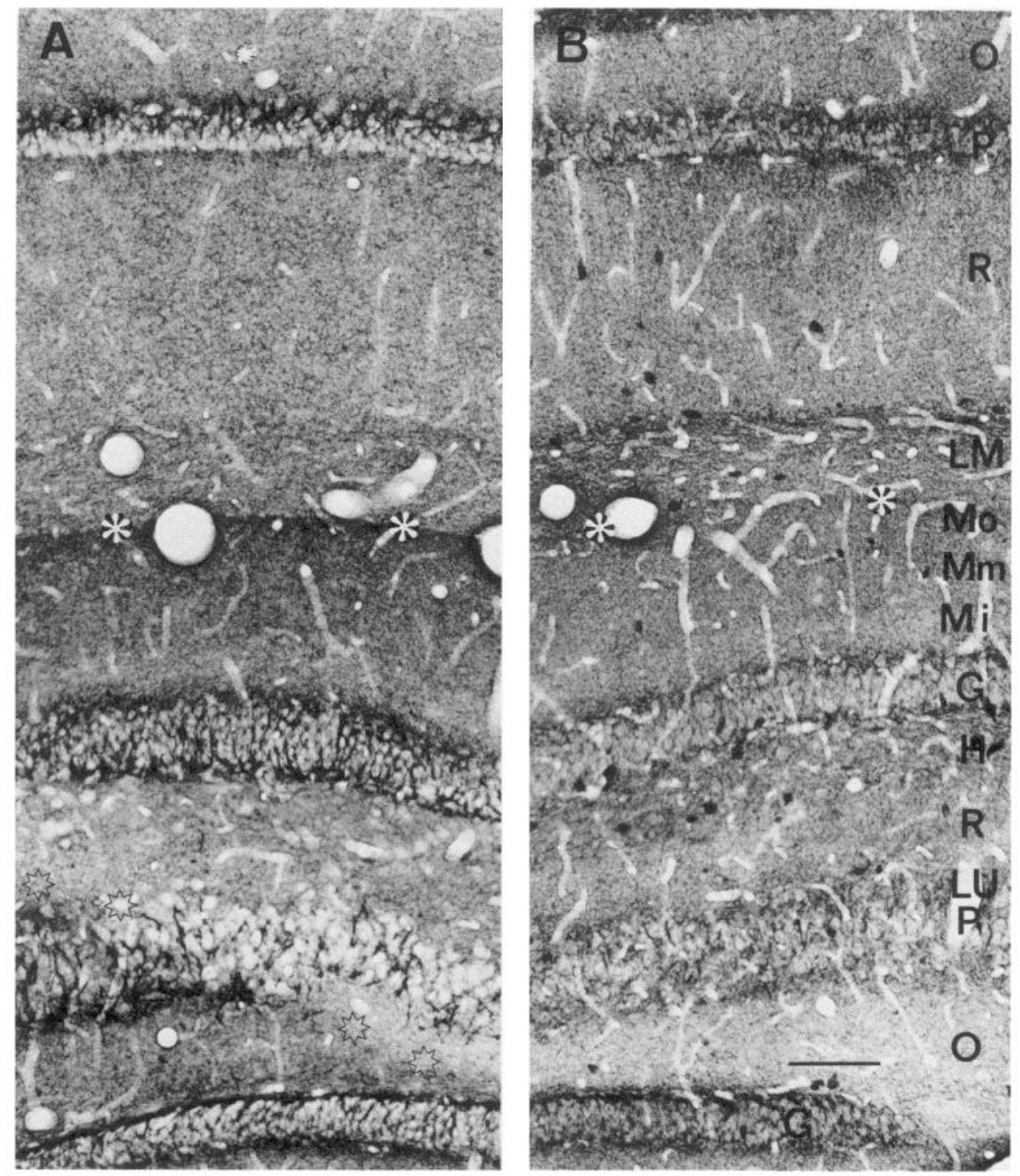

Substantia nigra, a brain area known to be very rich in GABA (biochemistry: Okada et al., 1971; Balcom et al., 1975; immunocytochemistry: Ottersen and Storm-Mathisen, 1984b) and glutamate decarboxylase (GAD) (Ribak et al., 1976; Mugnaini and Oertel, 1985), was strongly immunoreactive for both GABATp and GABA (Fig. 3). However, the GABA antiserum gave a more intense staining than the GABA-Tp antiserum in the substantia nigra in sections where neighboring areas showed similar staining intensities with the 2 antisera (Fig. $3, A, B$ ). The GABA$\mathrm{Tp}$ immunoreactivity appeared slightly more intense in pars compacta than in pars reticulata (Fig. $3 \mathrm{~A}$ ), while the GABA immunoreactivity was more intense in pars reticulata (Fig. $3 B$ ).

Also in other parts of the diencephalon/mesencephalon (Fig. 3) GABA-Tp and GABA were similarly distributed, corresponding in general to the picture previously described for GABA (Ottersen and Storm-Mathisen, 1984c) and GAD (Ohara et al., 1983). Both immunoreactivities were higher than average in the dorsal and ventral divisions of the lateral geniculate body and in the anterior and posterior pretectal nuclei, as well as in the olivary pretectal nucleus and the nucleus of the optic tract, the periaqueductal gray, and the interpeduncular nucleus, whereas the lateroposterior thalamic nucleus (particularly its ventral part) was less strongly stained than average. However, GABA staining was relatively more intense than GABA-Tp staining in the intergeniculate leaflet, while the opposite was the case for the posterior complex of the thalamus and, particularly, for the interpeduncular nucleus.

In the neocortex, both GABA-Tp and GABA immunoreactivity were localized in fairly uniformly distributed "puncta" and fibers, with GABA immunoreactivity present also in numerous cell bodies in all layers. In the corpus callosum there was faint staining of a few GABA- and GABA-Tp-positive fibers (not shown).

In the hippocampus and dentate gyrus (Figs. 3, 4), GABATp immunoreactivity was highest at the basal aspect of the pyramidal and granular cell layers. GABA-Tp immunoreactivity was also high in the intermediate and outer zones of the dentate molecular layer, with maximum intensity near the hippocampal fissure (Fig. $4 A$ ). The distribution of GABA immunoreactivity was essentially similar to that of GABA-Tp, except 

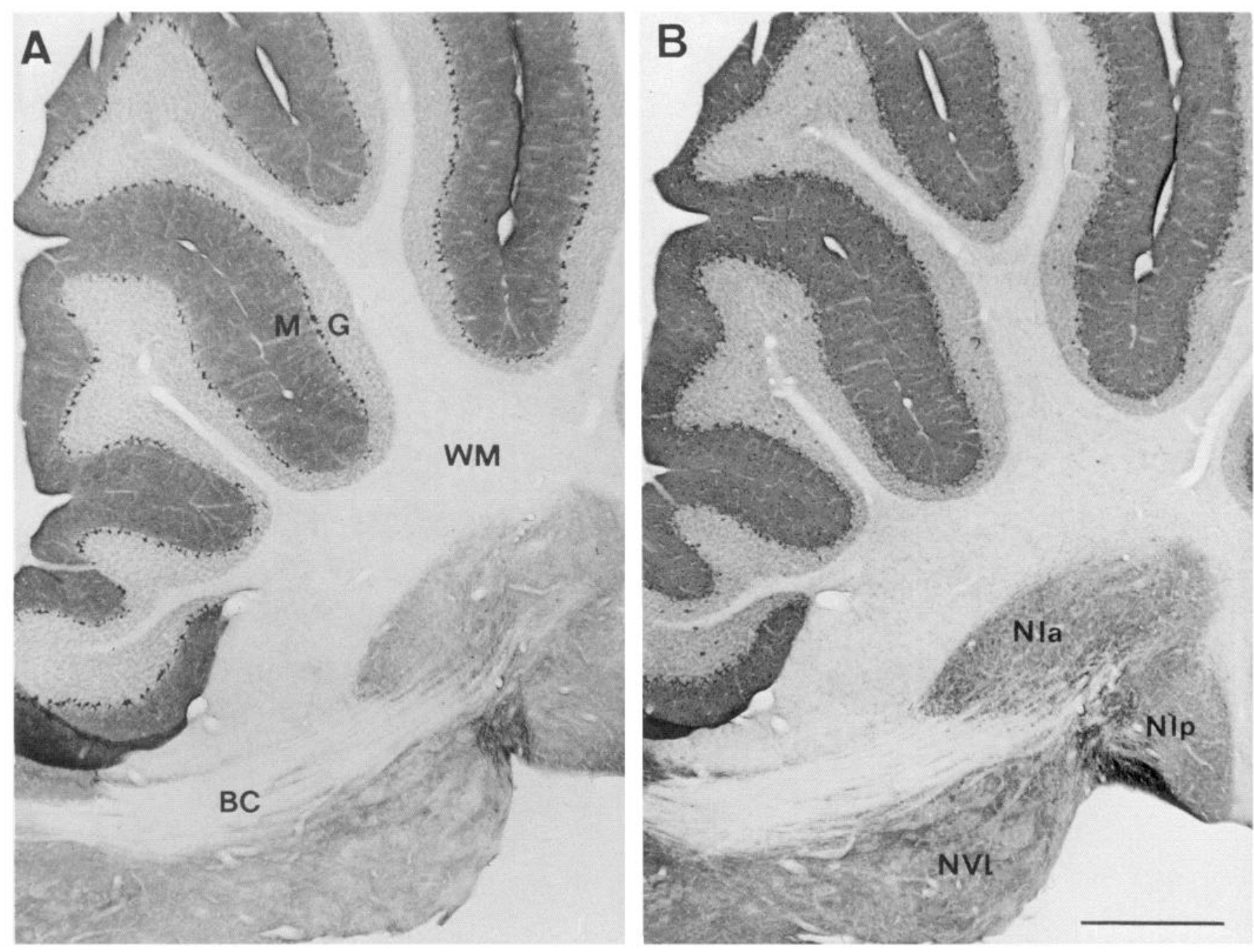

Figure 5. GABA-Tp $(A)$ and GABA $(B)$ in adjacent parasagittal sections (about $2.2 \mathrm{~mm}$ from midline) of the cerebellum and brain stem. Specimen preparation as in Figure 3. Abbreviations: $B C$, brachium conjunctivum; $G$ and $M$, granular and molecular layers of cerebellar cortex; NIa and NIp, nucleus interpositus anterior and posterior; $N V l$, nucleus vestibularis lateralis; $W M$, central cerebellar white matter. Note the similar laminar distributions of GABA-Tp and GABA in $G$ and $M$, but that GABA-Tp is relatively weaker in the target nuclei of the Purkinje cell axons (NIa, NIp, NVl) and virtually negative in WM. (Dark areas between NIp and NVl are due to foldings of the sections.) Scale bar, $500 \mu \mathrm{m}$.

that (1) numerous nonprincipal cell bodies were stained, (2) fibers were relatively less conspicuous, (3) the neuropil staining was about equally intense at the apical as at the basal aspect of the granular and pyramidal cell layers, and (4) whereas there was no obvious peak of immunoreactivity at the surface of the dentate molecular layer, a peak was seen at the junction of the stratum radiatum and stratum lacunosum moleculare of CA1 (Fig. 4B).

In the cerebellum, GABA-Tp immunoreactivity was confined to basket-cell axons around the somata and the axon-hillocks of Purkinje cells (the "pinceau"), and to fibers and terminallike puncta in the molecular and granular layers (Figs. 5A, 6A). GABA immunoreactivity was present in the same elements, but was less concentrated around the bases of Purkinje cells and more concentrated in the glomeruli, and occurred also in cell bodies of basket, stellate, and Golgi neurons (Figs. $5 B, 6 B$ ). In the deep cerebellar nuclei (Fig. 5, $A, B$ ) immunoreactivity for GABA, and to a lesser extent for GABA-Tp, was found in axons and nerve terminal-like structures. GABA immunoreactivity was found also in cell bodies of small neurons. No glial cell bodies were GABA-Tp positive in any of the regions examined.

\section{Electron microscopy}

The ultrastructural studies support and extend the light microscopic findings. GABA-Tp-positive axons and terminals were found around Purkinje cell bodies, particularly in the pinceau area, in the cerebellum (Figs. 7-9). The labeled axonal profiles in the pinceau represent those of basket cells (Figs. 8, 9D). In the molecular layer, labeled terminals may belong to stellate or basket cells (Fig. 9, $A, B$ ). Golgi cell axons were also labeled (Fig. $9 \mathrm{C}$ ), but less intensely, in agreement with the light microscopic results. The parent cell bodies of all the 3 types of interneuron were negative (not shown). Parallel, mossy, and climbing fibers, as well as Purkinje and granule cell bodies, were unlabeled. The staining seemed to be confined mainly to the terminal and preterminal axon. Structures within the terminal (plasma membrane, synaptic vesicles, mitochondria, neurofilaments) appeared to be covered with reaction product on their cytosolic 

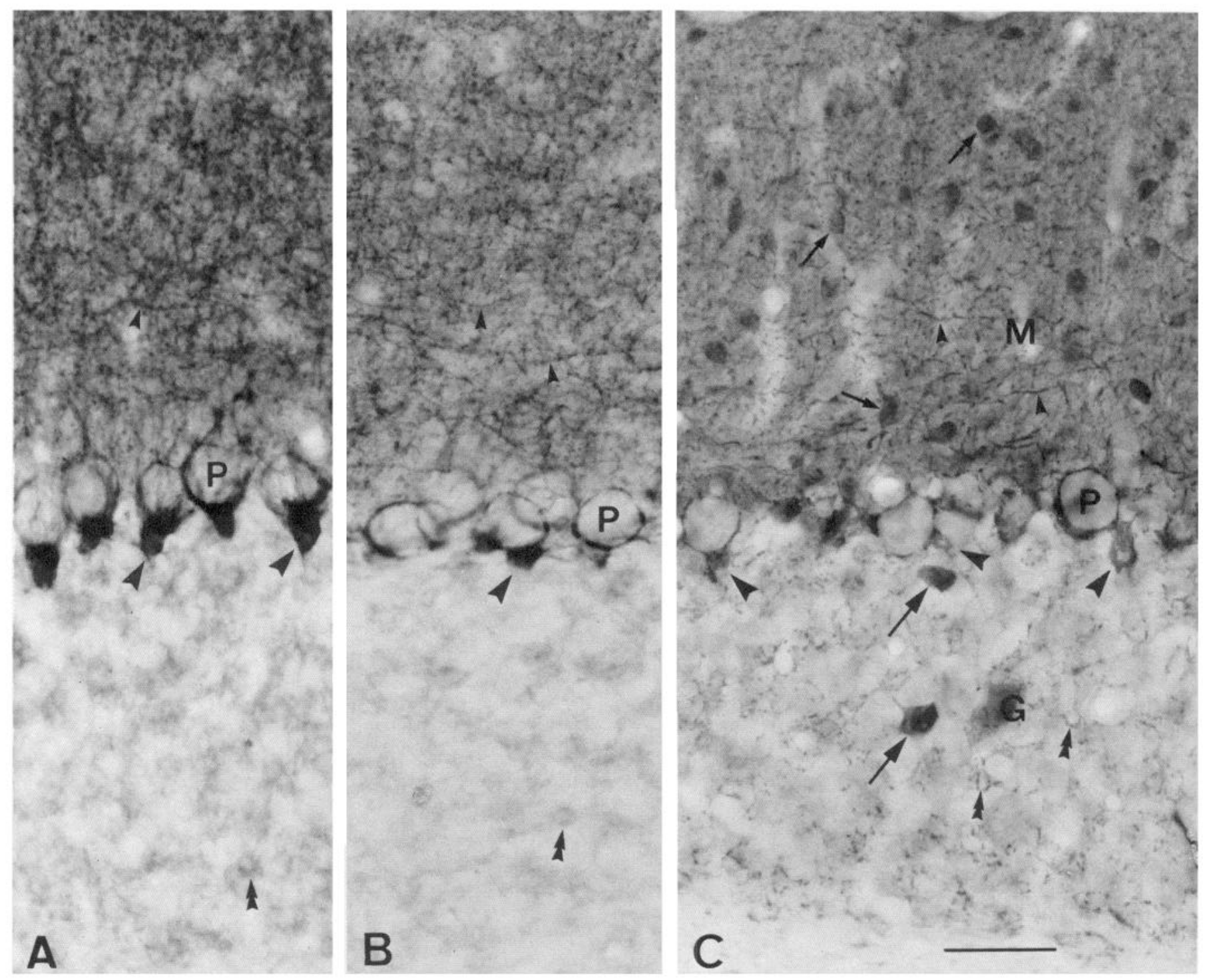

Figure 6. Localization of GABA-Tp at 2 different staining intensities $(A, B)$ and GABA $(C)$ in parasagittal sections of the cerebellar cortex. Specimen preparation as in Figure 3. Abbreviations: $G$ and $M$, granular and molecular layers; $P$, Purkinje cells; larger arrows, Golgi cells; smaller arrows, stellate or basket cells; big arrowheads, concentration of GABAergic axons and terminals around axon hillock of Purkinje cells, the pinceau area; small arrowheads, stained fibers in layer $M$; double arrowheads, glomeruli. Note that GABA-Tp and GABA are found in similar fibers and nerve terminal-like puncta, but that GABA-Tp is more concentrated in the pinceau, while GABA is more concentrated in terminals in the glomeruli and also occurs in cell bodies. Scale bar, $100 \mu \mathrm{m}$.

aspect (Figs. 8, inset; 9A). The interior of mitochondria was unstained. In all regions, anti-GABA and anti-GABA-Tp appeared to label the same types of terminals and axons. This could be demonstrated by double-labeling of tissue that had been treated with GABA-Tp antibodies (preembedding ABC procedure), as well as GABA antibodies (postembedding immunogold procedure). In such specimens, the 2 immunoreactivities were found to coexist in the same terminals (Fig. 10).

Of particular interest was the finding that glial processes were labeled with anti-GABA-Tp (Figs. 7; 9, $A, B$ ) but not with antiGABA. This was observed in all the areas studied electron microscopically (i.e., in the molecular and the granular layers of the cerebellum, in the hippocampus, and in the substantia nigra). The staining of glial processes with the GABA-Tp antiserum was particularly evident in the substantia nigra (not shown). In none of the areas examined did this antiserum stain glial cell bodies.

\section{Discussion}

The present study describes the immunocytochemical localization of GABA-Tp in rat brain, using polyclonal antibodies raised against the pure transporter (Radian et al., 1986). The spot-test (Ottersen and Storm-Mathisen, 1984a) showed that these antibodies were specific for the GABA-Tp and did not bind to other antigens such as irrelevant membrane proteins or GABA itself (fixed to brain proteins by glutaraldehyde). Also, addition of GABA-Tp to the incubation medium containing the antibodies resulted in strong inhibition of the immunocytochemical reaction in brain tissue.

The localization of GABA-Tp as revealed immunocytochem- 


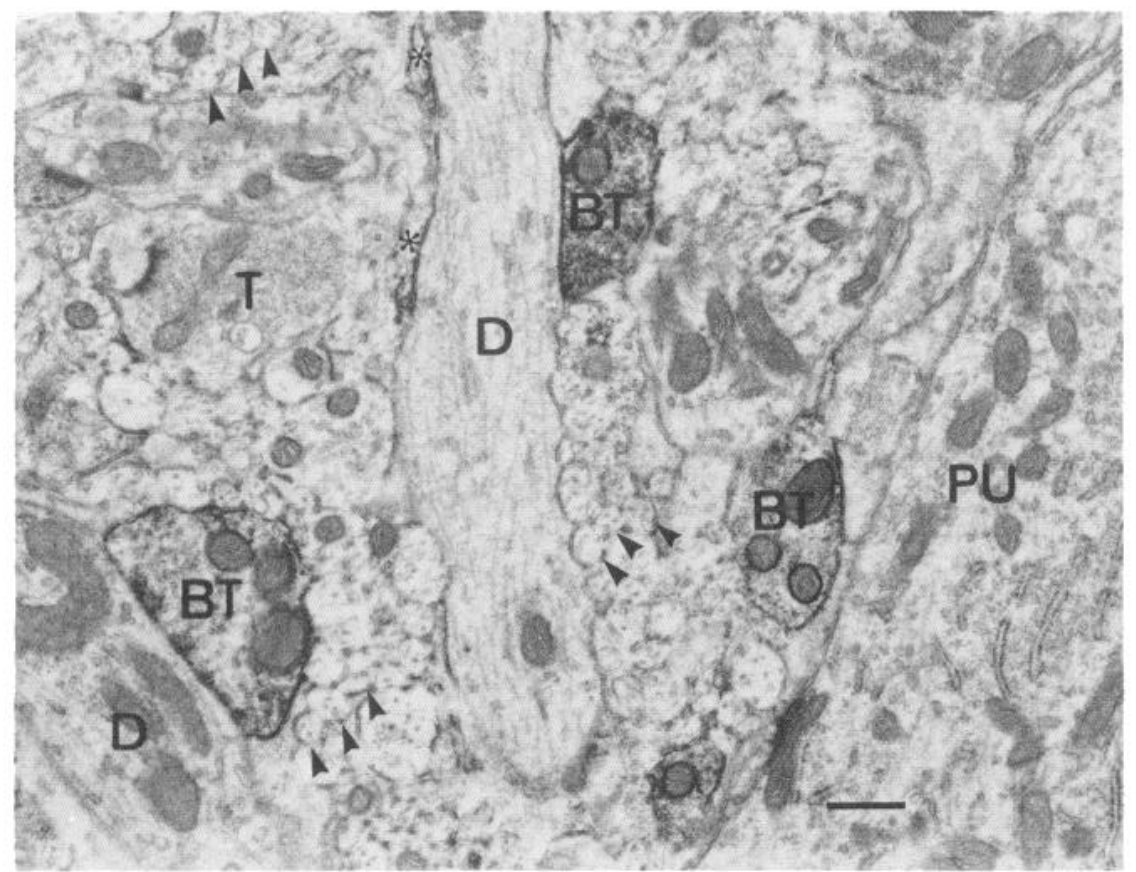

Figure 7. Electron micrograph of GABA-Tp immunoreactive structures in molecular layer of cerebellar cortex close to the Purkinje cells. Tissue fixed in $3 \%$ formaldehyde $+3 \%$ glutaraldehyde, antibody dilution 1:10, embedded in Spurr's resin. Abbreviations: $B T$, immunoreactive boutons, probably of basket cells, 2 of them contacting dendritic shafts; $D$, dendrites, the central one probably of a non-Purkinje cell; $P U$, Purkinje cell perikaryon; $T$, nonimmunoreactive terminal in contact with dendritic spine; arrowheads, parallel fibers (nonimmunoreactive); asterisks, immunoreactive glial profiles. Note that immunoreactivity is restricted to boutons and glial lamellae. Scale bar, 0.5 $\mu \mathrm{m}$.

ically is in agreement with that previously demonstrated by autoradiography after uptake of ${ }^{3} \mathrm{H}-\mathrm{GABA}$ (Hökfelt and Ljungdahl, 1972; Taxt and Storm-Mathisen, 1979, 1984), although a direct comparison of these 2 techniques will necessarily be limited by the fact that autoradiography cannot match the high resolution attainable by electron microscopic immunocytochemistry. The use of anti-GABA in parallel with anti-GABA$T p$ revealed very similar labeling patterns in all brain areas examined. GABA-Tp-positive terminals and axons could be identified as belonging to bonafide GABAergic cells, such as cerebellar basket and stellate cells. Correspondingly, doublelabeling experiments showed that the GABA-Tp-immunoreactive terminals and axons also contained endogenous GABA.

Although the labeling patterns for GABA-Tp and GABA were basically similar, certain differences were apparent. While variation in the detectabilities of antigens cannot be strictly excluded, most of the differences observed here may be interpreted as real variation among sites in the relative contents of GABA-Tp and GABA. Notably, perikarya of presumed GABAergic neurons were positive for GABA but negative for GABA-Tp. This finding is consistent with the notion that a high concentration of the transporter will be functionally less relevant in the perikaryon than in the terminals and suggests that cell body accumulation of radiolabeled GABA seen after in vivo or in vitro application is secondary to nerve terminal uptake and retrograde axonal transport. Another discrepancy is the concentration of GABA-Tp (relative to GABA) at the basal aspect of the hippocampal pyramidal layer and, to a lesser extent, at the basis of the dentate granular layer. ${ }^{3} \mathrm{H}-\mathrm{GABA}$ localized by autoradiography after uptake also tends to be concentrated basally, but less so than GABA-Tp (Taxt and Storm-Mathisen, 1979, 1984). This could be due to intra-axonal migration of ${ }^{3} \mathrm{H}-\mathrm{GABA}$ following uptake. The concentration of GABA-Tp close to the bases of the hippocampal pyramids may be related to the presence of the terminals of the axoaxonic (presumed GABAergic) cell in this location (Somogyi et al., 1983). Axoaxonic GA-
BAergic synapses have also been described on the granular cell axons (Kosaka et al., 1984). As the axoaxonic cells are high in parvalbumin and probably sustain high-frequency firing (Katsumaru et al., 1988; also see Sloviter, 1989), it may be speculated that they require a high concentration of GABA-Tp in their terminals to cope with the released GABA. In general, exact correspondence between the distributions of GABA-Tp and GABA cannot be expected since regional differences in GABA turnover and release may imply different demands on the uptake and on the stores of the transmitter. Thus, differences among neurons in the ratio of GABA uptake and GAD activity have been observed (Storm-Mathisen, 1975; see below).

The electron microscopic observations revealed an additional localization of GABA-Tp in glial processes. Astroglia have been reported to exhibit high-affinity net GABA influx (Hertz et al., 1978). Indeed, it was suggested that they may be of major importance for the termination of GABAergic transmission (e.g., Schousboe et al., 1977; Hertz et al., 1978). Since GABA-transaminase, which is responsible for the degradation of GABA, has high activity in astrocytes, and since GAD is absent, the GABA concentration in the glial processes is probably very low under most conditions (Schousboe et al., 1977; Schousboe, 1981) and is generally not detectable immunocytochemically (Ottersen and Storm-Mathisen, 1984a; Somogyi et al., 1985). However, GABA immunoreactivity has recently been reported to occur in some populations of glial cell bodies (Blomqvist and Broman, 1988). On the other hand, GAD is present in nerve terminals, and GABA itself is partly sequestered in storage organelles (Sihra and Nicholls, 1987; Hell et al., 1988), and is thereby protected from metabolic degradation.

Among the regions examined, substantia nigra had the most prominent glial localization of GABA-Tp, and in this structure its localization in nerve endings was very sparse. This is consistent with the observation that nigral GABA uptake is low relative to GAD and is relatively less affected than GAD after degeneration of the striatonigral pathway following axotomy 


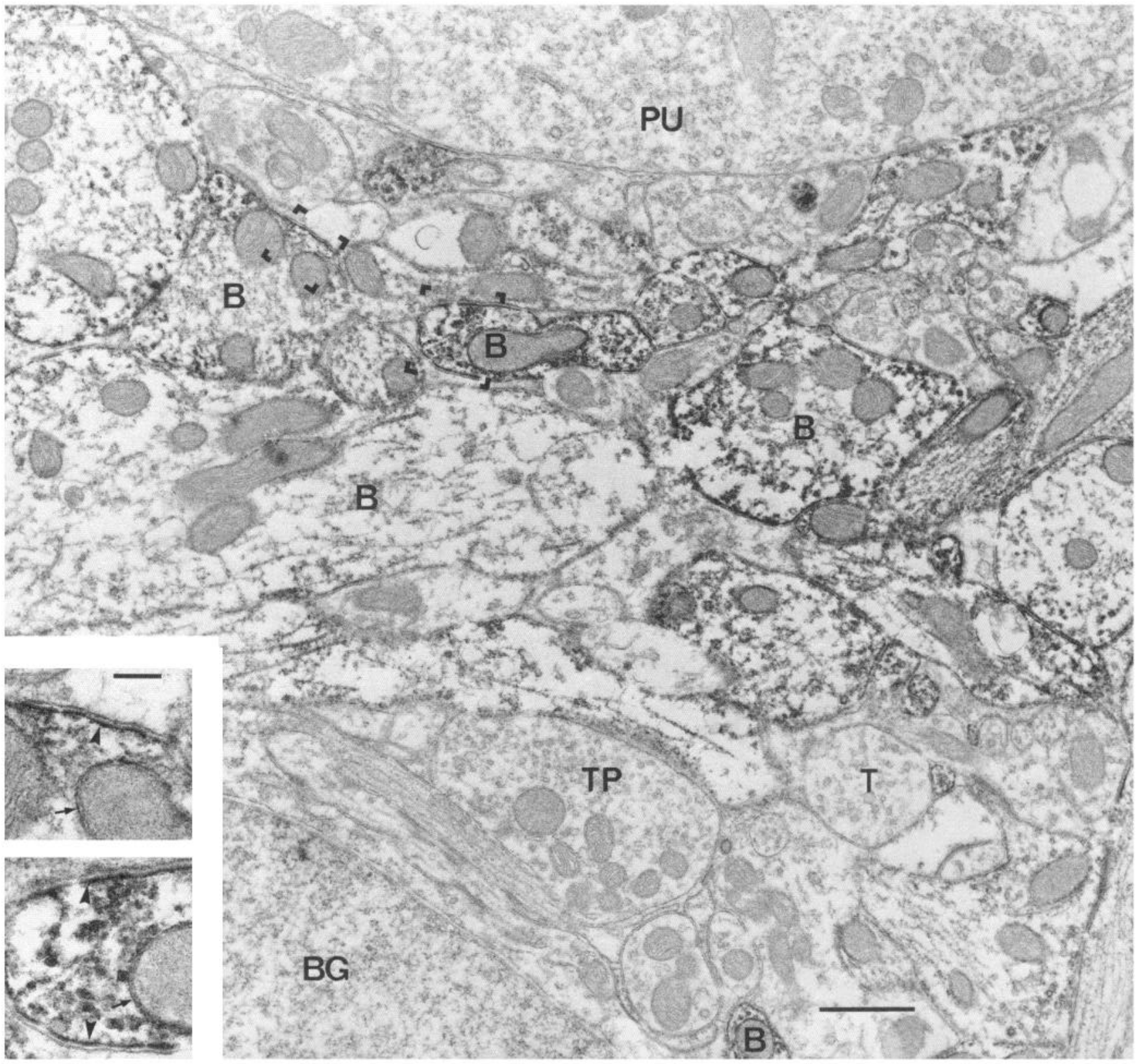

Figure 8. Electron micrograph of GABA-Tp immunoreactive structures in the pinceau area. Tissue fixed in 5\% glutaraldehyde, antibody dilution 1:10, embedded in Epon. Insets show boxed areas at higher magnification. Abbreviations: $B$, axons and terminals, most likely of basket cells, showing varying degrees of labeling (probably as a result of varying degrees of antibody penetration); $B G$, cell body of likely Bergmann glia, unlabeled; $T$, unlabeled bouton with round vesicles; $T P$, unlabeled bouton with pleomorphic vesicles. Note that the reaction product appears to be concentrated on the cytosolic side of plasma membranes (arrowheads) and of organelles such as mitochondria (arrows) in the labeled structures. Scale bars, 0.8 $\mu \mathrm{m}$; for insets, $0.17 \mu \mathrm{m}$.

(Storm-Mathisen, 1975). Similarly, the moderate immunostaining for GABA-Tp relative to GABA in the cerebellar and lateral vestibular nuclei is consistent with the lack of demonstrable uptake (perikaryal: Hökfelt and Ljungdahl, 1972; terminal: Storm-Mathisen, 1975) and retrograde axonal transport (Wiklund et al., 1983) of ${ }^{3} \mathrm{H}-\mathrm{GABA}$ in Purkinje cells.
The ability of GABA-Tp antibodies to recognize antigenic determinants on neuronal as well as on glial elements suggests that the 2 types of transporter share common determinants, but it is as yet impossible to predict how similar they are. However, it is clear that they are not identical. Biochemical studies have shown that various analogs of GABA have a differential effect

Figure 9. Examples of GABA-Tp-immunoreactive structures in the cerebellar molecular $(A, B)$ and granular $(C, D)$ layers, and $(D)$ the pinceau formation. Specimen preparation as in Figure 8. Abbreviations: $B S T$, immunoreactive basket or stellate cell terminals; $B$, immunoreactive likely basket cell axon with en passant vesicle-containing swellings; $D$, dendrite of non-Purkinje cell in contact with a BST and 2 probable parallel fiber 

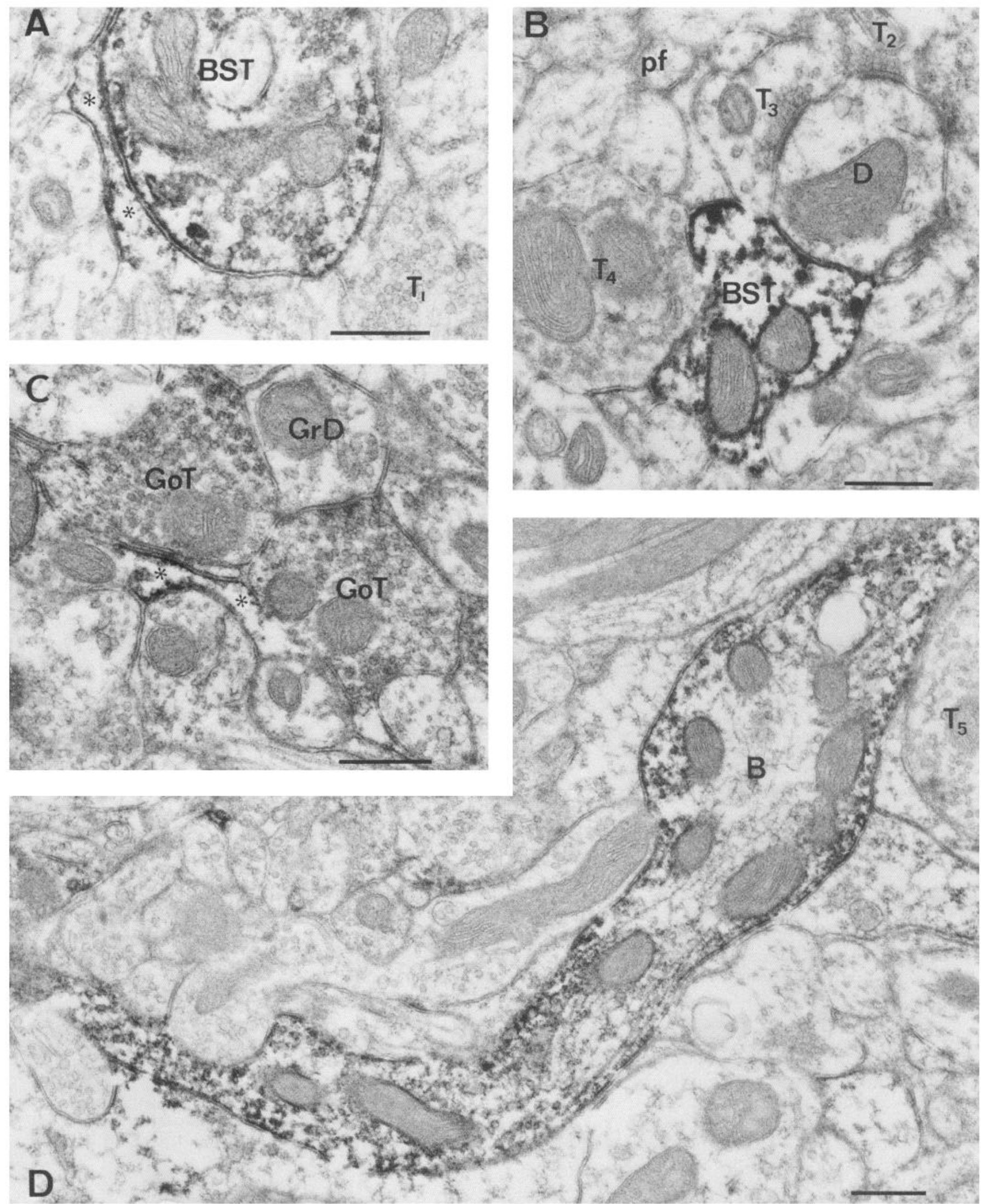

terminals $(T 2, T 3)$; $G o T$, weakly labeled Golgi axon terminals; $G r D$, granular cell dendrite in contact with GoT in a glomerulus; $p f$, parallel fibers; $T 1-T 5$, unlabeled terminals, the last 2 with pleomorphic vesicles, possibly from Golgi neurons; asterisks, immunoreactive glial lamellae. Note the selective labeling of glial lamellae and of axons/terminals of the 3 types of cerebellar inhibitory interneurons; in the labeled structures, the reaction product appears along the cytosolic surfaces of the plasma membrane, synaptic vesicles, and mitochondria. Scale bars, $0.5 \mu \mathrm{m}$. 


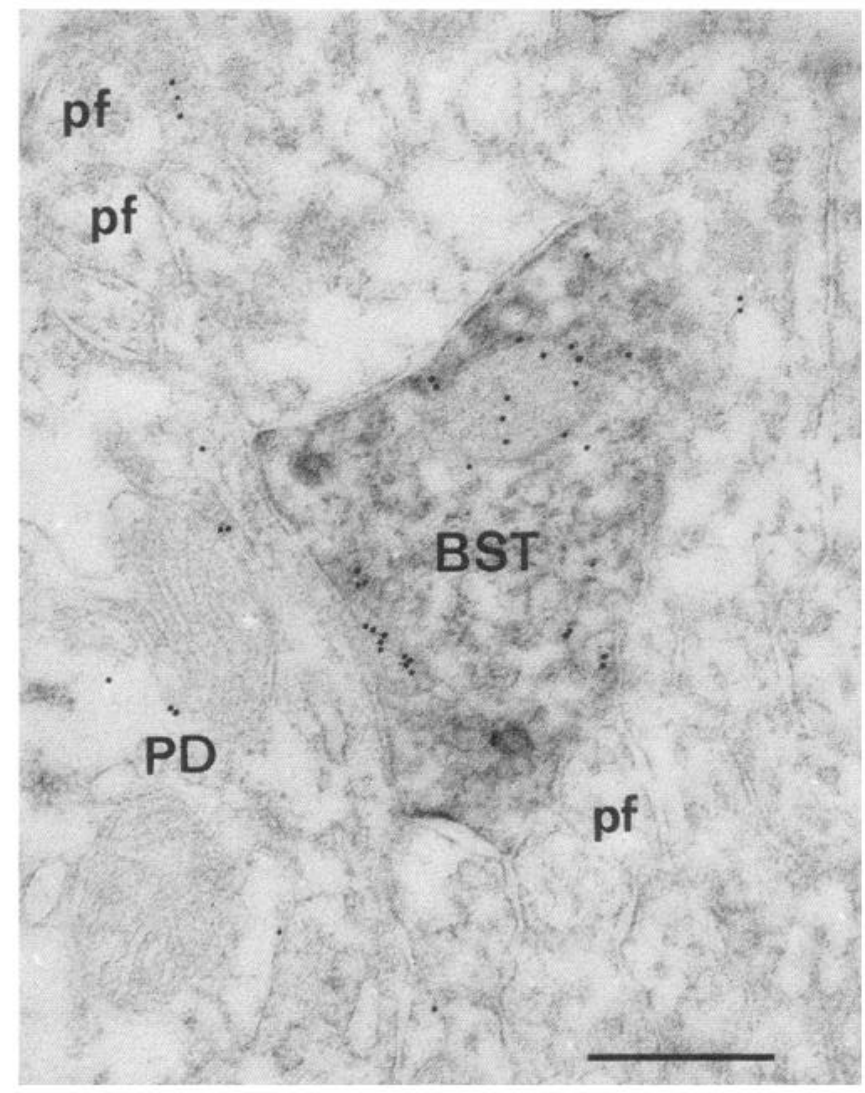

Figure 10. Double labeling of GABA-Tp (preembedding immunoperoxidase) and GABA (postembedding immunogold) in the cerebellar molecular layer. Specimen prepared as in Figure 8, then reacted with GABA antibody as described in Materials and Methods. Abbreviations: $B S T$, doubly labeled basket or stellate cell bouton; $P D$, likely Purkinje cell dendrite in contact with BST; $p f$, parallel fibers. (The light counterstain facilitates the visualization of the gold particles.) Note high density of gold particles over immunoperoxidase-labeled BST. Scale bar, 0.5 $\mu \mathrm{m}$.

on GABA transport in neuronal versus glial preparations (Iversen and Kelly, 1975; Schon and Kelly, 1975; Johnston and Stephanson, 1976; Neal and Bowery, 1977; Schousboe, 1981; Larsson et al., 1983). For instance, $\beta$-alanine is an inhibitor of glial GABA transport (Schon and Kelly, 1975; Johnston and Stephanson, 1976; Schousboe, 1981), while other compounds, such as cis-3-aminocyclohexane carboxylic acid, are selective for neuronal GABA transport (Neal and Bowery, 1977; Larsson et al., 1983). This indicates a heterogeneity in transporter structure, at least with regard to the substrate recognition site. Hopefully, it will be possible to determine the extent of homology when the gene(s) for the transporter(s) is (are) cloned. Future purification of the glial transporter, possibly based on different sensitivities to inhibition, may also be of help in discrimination between the 2 transporters. Alternatively, development of monoclonal antibodies against the neuronal and/or glial transporter may facilitate discrimination, possibly also at the immunocytochemical level.

The GABA transporter present in synaptic vesicles (Fykse and Fonnum, 1988; Hell et al., 1988) shows biochemical properties quite distinct from those of GABA-Tp of plasma membranes and is unlikely to have contaminated the purified GABA$\mathrm{Tp}$ against which the antibodies used in the present study were raised (Radian et al., 1986). In some of the immunoreactive nerve terminals, the surface of synaptic vesicles, like that of other organelles, was stained. This is probably a sign of intraterminal diffusion of the diaminobenzidine reaction product, an interpretation supported by the observation that at low labeling intensity the reaction product occurred close to the plasma membrane only. The latter finding suggests that the plasma membrane is the site of highest concentration of antigen. The fact that the immunoperoxidase reaction product appeared to be confined to the interior of the labeled cellular processes suggests that the antigenic sites of the GABA-Tp most frequently face the cytosolic side of the plasma membrane. This would be consistent with GABA-Tp being a transmembrane protein. To obtain further information on the intracellular distribution of the GABA-Tp, it will be necessary to apply other detection methods, such as immunogold techniques, which reveal the location of the antigenic site with greater precision.

The data presented here indicate that immunocytochemical localization of GABA-Tp may be used as a presynaptic marker of putative GABAergic terminals. In comparison with autoradiographic localization of GABA uptake, it offers better resolution. It may also serve to distinguish between GABA-containing cells able to accumulate GABA by membrane transport and ones receiving GABA by passive transfer from neighboring cells via gap junctions (nexus; Zucker et al., 1984; cf. Cohen and Sterling, 1986).

In a wider perspective, it should be noted that many features characteristic of GABAergic synapses and considered important criteria for establishing the transmitter identity can now be addressed by immunocytochemistry at the ultrastructural level. These include the nerve terminal contents of the endogenous transmitter (Storm-Mathisen et al., 1983; Somogyi et al., 1985) and the synthesizing enzyme (McLaughlin et al., 1974), depletion of the transmitter under conditions known to induce synaptic release (Storm-Mathisen et al., 1986; Ottersen et al., 1990), the presence of a postsynaptic GABA receptor (Schoch et al., 1985; de Blas et al., 1988; Houser et al., 1988), and, as demonstrated in this report, the endowment of a mechanism responsible for terminating transmitter action. An important task for future research will be to find conditions that allow several of these features to be studied in the same tissue section, thus opening for a more penetrating analysis of GABAergic synapses than is possible with immunocytochemistry based on a single marker. Such an approach is desirable in view of the apparent mismatch between individual markers observed in many transmitter systems (Herkenham, 1987), including the GABA system (Yazulla et al., 1989).

\section{References}

Balcom, G. J., R. H. Lenox, and J. L. Meyerhoff (1975) Regional $\gamma$-aminobutyric acid levels in rat brain determined after microwave fixation. J. Neurochem. 24: 609-613.

Bennett, J. P., Jr., A. H. Mulder, and S. H. Snyder (1974) Neurochemical correlates of synaptically active amino acids. Life Sci. 15: 1045-1056.

Blomqvist, A., and J. Broman (1988) Light and electron microscopic immunohistochemical demonstration of GABA-immunoreactive astrocytes in the brain stem of the rat. J. Neurocytol. 17: 629-637.

Castel, M., J. Morris, Y. Ben-Barak, R. Timberg, N. Sivan, and H. Gainer (1985) Ultrastructural localization of immunoreactive neurophysins using monoclonal antibodies and protein A-gold. J. Histochem. Cytochem. 33: 1015-1025.

Cohen, E., and P. Sterling (1986) Accumulation of $\left[{ }^{3} \mathrm{H}\right] \mathrm{glycine}$ by cone bipolar neurons in the cat retina. J. Comp. Neurol. 250: 1-7. 
de Blas, A. L., J. Victoria, and P. Friedrich (1988) Localization of $\mathrm{GABA}_{\mathrm{A}}$ receptor in the rat brain with a monoclonal antibody to the $57.000 \mathrm{Mr}$ peptide of the $\mathrm{GABA}_{\mathrm{A}}$ receptor/benzodiazepine receptor/ Cl-channel complex. J. Neurosci. 8: 602-614.

Fykse, E. M., and F. Fonnum (1988) Uptake of $\gamma$-aminobutyric acid by a synaptic vesicle fraction isolated from rat brain. $J$. Neurochem. 50: $1237-1242$.

Hell, J. W., P. R. Maycox, H. Stadler, and R. Jahn (1988) Uptake of GABA by rat brain synaptic vesicles isolated by a new procedure. EMBO J. 7: 3023-3029.

Herkenham, M. (1987) Mismatches between neurotransmitter and receptor localizations in brain: Observations and implications. Neuroscience 23: 1-38.

Hertz, L., P. H. Wu, and A. Schousboe (1978) Evidence for net uptake of GABA into mouse astrocytes in primary cultures-its sodium dependence and potassium independence. Neurochem. Res. 3: 313-323.

Houser, C. R., R. W. Olsen, J. G. Richards, and H. Möhler (1988) Immunocytochemical localization of benzodiazepine/GABA $A_{A}$ receptors in the human hippocampal formation. J. Neurosci. 8: 1370-1383.

Hökfelt, T.., and A. Ljungdahl (1972) Autoradiographic identification of cerebellar and cerebral cortical neurons accumulating labelled gamma-aminobutyric acid [ $\left.{ }^{3} \mathrm{H}-\mathrm{GABA}\right]$. Exp. Brain Res. 14: 354-362.

Hsu, S. M., L. Raine, and H. Fanger (1981) Use of avidin-biotinperoxidase complex $(\mathrm{ABC})$ in immunoperoxidase techniques: $\mathrm{A}$ comparison between $A B C$ and unlabeled antibody (PAP) procedures. $J$ Histochem. Cytochem. 29: 577-580.

Iversen, L. L. (1971) Role of transmitter uptake mechanisms in synaptic neurotransmission. Br. J. Pharmacol. 41: 571-591.

Iversen, L. L. (1973) Catecholamine uptake processes. Br. Med. Bull. 29: $130-135$

Iversen, L. L., and J. S. Kelly (1975) Uptake and metabolism of $\gamma$-aminobutyric acid by neurones and glial cells. Biochem. Pharmacol. 24: 933-938

Johnston, G. A. R., and A. L. Stephanson (1976) Inhibitors of the glial uptake of $\beta$-alanine in rat brain slices. Brain Res. 102: 374-378.

Jones, E. G. (1983) The thalamus. In Chemical Neuroanatomy, P. C. Emson, ed., pp. 257-293, Raven, New York.

Kanner, B. I. (1978) Active transport of $\gamma$-aminobutyric acid by membrane vesicles isolated from rat brain. Biochemistry 17: 1207-1211.

Kanner, B. I. (1983) Bioenergetics of neurotransmitter transport. Biochem. Biophys. Acta 726: 293-316.

Katsumaru, H., T. Kosaka, C. W. Heizmann, and K. Hama (1988) Gap junctions on GABAergic neurons containing the calcium-binding protein parvalbumin in the rat hippocampus ( $\mathrm{CAl}$ region). Exp. Brain Res. 72: 363-370.

Kosaka, T., K. Hama, and J.-Y. Wu (1984) GABAergic synaptic boutons in the granule cell layer of rat dentate gyrus. Brain Res. 293 353-359.

Kuhar, J. M. (1973) Neurotransmitter uptake: A tool in identifying neurotransmitter-specific pathways. Life Sci. 13: 1623-1634.

Larsson, O. M., G. A. R. Johnston, and A. Schousboe (1983) Differences in uptake kinetics of cis-3-aminocyclohexane carboxylic acid into neurons and astrocytes in primary cultures. Brain Res. 260: 279285.

McLaughlin, B. J., J. G. Wood, K. Saito, R. Barber, J. E. Vaughn, E. Roberts, and J.-Y. Wu (1974) The fine structural localization of glutamate decarboxylase in synaptic terminals of rodent cerebellum. Brain Res. 76: 377-391.

Mugnaini, E., and W. H. Oertel (1985) GABA neurons as revealed by GAD immunocytochemistry. In Ilandbook of Chemical Neuroanatomy, Vol. 4, A. Björklund and T. Hökfelt, eds., pp. 436-622, Elsevier, Amsterdam.

Neal, M. J., and N. G. Bowery (1977) Cis-3-aminocyclohexane-carboxylic acid: A substrate for the neuronal GABA transport system. Brain Res. 138: 169-174.

Ohara, P. T., A. R. Lieberman, S. P. Hunt, and J.-Y. Wu (1983) Neural elements containing glutamic acid decarboxylase (GAD) in the dorsal lateral geniculate nucleus of the rat; immunohistochemical studies by light and electron microscopy. Neuroscience 8: 189-211.

Okada, Y., C. Nitsch-Hassler, J. S. Kim, I. J. Bak, and R. Hassler (1971) Role of $\gamma$-aminobutyric acid (GABA) in the extrapyramidal motor system. I. Regional distribution of GABA in rabbit, rat, guinea pig and baboon CNS. Exp. Brain Res. 13: 514-518.

Ottersen, O. P., and J. Storm-Mathisen (1984a) Glutamate- and GABAcontaining neurons in the mouse and rat brain, as demonstrated with a new immunocytochemical technique. J. Comp. Neurol. 229:374392.

Ottersen, O. P., and J. Storm-Mathisen (1984b) Neurons containing or accumulating transmitter amino acids. In Handbook of Chemical Neuroanatomy, Vol. 3, A. Björklund and T. Hökfelt, eds., pp. 141239, Elsevier, Amsterdam.

Ottersen, O. P., and J. Storm-Mathisen (1984c) GABA - itaining neurons in the thalamus and pretectum of the rodent. Anat. Embryol. 170: $197-207$

Ottersen, O. P., J. Storm-Mathisen, S. Madsen, S. Skumlien, and J. Strømhaug (1986) Evaluation of the immunocytochemical method for amino acids. Med. Biol. 64: 147-158.

Ottersen, O. P., J. Storm-Mathisen, and P. Somogyi (1988) Glycinelike and GABA-like immunoreactivities are colocalized in a subpopulation of Golgi cell terminals in the rat cerebellum: An electron microscopic study with the postembedding immunogold staining technique. Brain Res. 450: 342-353.

Ottersen, O. P., I. Storm-Mathisen, and J. H. Laake (1990) Quantitative immunocytochemistry of glycine. In Glycine Neurotransmission, O. P. Ottersen and J. Storm-Mathisen, eds., Wiley, Chichester U.K. (in press).

Radian, R., and B. I. Kanner (1983) Stoichiometry of sodium and chloride-coupled $\gamma$-aminobutyric acid transport by synaptic plasma membrane vesicles isolated from rat brain. Biochemistry $22: 1236-$ 1241.

Radian, R., and B. I. Kanner (1985) Reconstitution and purification of the sodium and chloride-coupled $\gamma$-aminobutyric acid transporter from rat brain. J. Biol. Chem. 260: 11859-11865.

Radian, R., A. Bendahan, and B. I. Kanner (1986) Purification and identification of the functional sodium and chloride-coupled $\gamma$-aminobutyric acid transport glycoprotein from rat brain. J. Biol. Chem. 261: 15437-15441.

Ribak, C. E., J. E. Vaughn, K. Saito, R. Barber, and E. Roberts (1976) Immunocytochemical localization of glutamate decarboxylase in rat substantia nigra. Brain Res. 116: 287-298.

Scalia, F. (1972) The termination of retinal axons in the pretectal region of mammals. J. Comp. Neurol. 145: 223-258.

Schoch, P., J. G. Richards, P. I Iaring, B. Takacs, C. Stahli, T. Stachelin, W. Haefely, and H. Möhler (1985) Co-localization of GABA $\mathrm{Ae}$ ceptors and benzodiazepine receptors in the brain shown by monoclonal antibodies. Nature 314: 168-171.

Schon, F., and J. S. Kelly (1975) Selective uptake of $\left[{ }^{3} \mathrm{H}\right] \beta$-alanine by glia: Association with the glial uptake system for GABA. Brain Res. 86: $243-257$

Schousboe, A. (1981) Transport and metabolism of glutamate and GABA in neurons and glial cells. Int. Rev. Neurobiol. 22: 1-45.

Schousboe, A., L. Hertz, and G. Svenneby (1977) Uptake and metabolism of GABA in astrocytes cultured from dissociated mouse brain hemispheres. Neurochem. Res. 2: 217-229.

Sihra, T. S., and D. G. Nicholls (1987) GABA can be released exocytotically from guinea-pig cortical synaptosomes. J. Neurochem. 49. 261-267.

Sloviter, R. S. (1989) Calcium binding protein (Calbindin-P28k) and parvalbumin immunocytochemistry: Localization in the rat hippocampus with specific reference to the selective vulnerability of hippocampal neurons to seizure activity. J. Comp. Neurol. 280: 183196.

Somogyi, P., M. G. Nunzi, A. Gorio, and A. D. Smith (1983) A new type of specific interneuron in the monkey hippocampus forming synapses exclusively with axon initial segments of pyramidal cells. Brain Res. 259: 137-142.

Somogyi, P., A. J. Hodgson, I. W. Chubb, B. Penke, and A. Eredi (1985) Antiserum to $\gamma$-aminobutyric acid: II. Immunocytochemical application to the central nervous system. J. Histochem. Cytochem. 33 . $240-248$

Sternberger, L. A. (1979) Immunocytochemistry, Wiley, New York.

Storm-Mathisen, J. (1975) High affinity uptake of GABA in presumed GABAergic nerve endings in rat brain. Brain Res. 84: 409-427.

Storm-Mathisen, J., A. K. Leknes, A. T. Bore, J. L. Vaalund, P. Edminson, F.-M. S. Haug, and O. P. Ottersen (1983) First visualization of glutamate and GABA in neurons by immunocytochemistry. Nature 301: 517-520.

Taxt, T., and J. Storm-Mathisen (1979) Tentative localization of glutamergic and aspartergic nerve endings in brain. J. Physiol. (Paris) 75: $677-684$ 
Taxt, T., and J. Storm-Mathisen (1984) L-glutamate in excitatory axon terminals in hippocampus: Autoradiographic and biochemical comparison with GABA and other amino acids in normal rats and in rats with lesions. Neuroscience 11:79-100.

Wiklund, L., H. Künzle, and M. Cuénod (1983) Failure to demonstrate retrograde labelling of cerebellar Purkinje cells after injection of ['II]GABA in Dieters' nucleus. Neurosci. Lett. 38: 23-28.
Yazulla, S., K. M. Studholme, J. Victoria, and A. L. de Blas (1989) Immunocytochemical localization of $\mathrm{GABA}_{\mathrm{A}}$ receptors in goldfish and chicken retinas. J. Comp. Neurol. 280: 15-26.

Zucker, C., S. Yazulla, and J.-Y. Wu (1984) Non-correspondence of [ $\left.{ }^{3} \mathrm{H}\right]-\mathrm{GABA}$ uptake and GAD localization in goldfish amacrine cells. Brain Res. 298: 154-158. 